and intestinal haemorrhage were regarded as the result of tuberculous ulceration of the intestines, and probably of tuberculosis more or less generalized throughout the body. Tuberculous ulceration of the intestines is, in our experience at least, hardly ever accompanied by profuse intestinal haemorrhage; but Professor Oeler speaks of having had several fatal cases from this cause. The occurrence of profuse haemorrhage of the stomach without haematemesis was presumably explained by the pressure exerted by the growth against the cardiac orifice, and to some extent by the presence of the oesophageal growth, conditions which would make vomiting impossible. Much stress cannot be laid on the obstructive influence of the latter, inasmuch as there was at no time any recognizable dysphagia. The same argument might, indeed; be raised with regard to the gastric growth; but it seems reasonable to believe that the gastric growth, which did not quite reach the cardiac orifice, did not obstruct that orifice when the stomach was passive, but that in vigorous contraction of the stomach, such as would induce vomiting in a bealthy person, the cardiac orifice became obstructed by the pressure of the growth. In other words, that the obstruction was valvular.

Borst: Die Lehre von den Geschuillsten, ii, 541

Clement: Virch. Arch, cxxxix, 35.

Fitterer: Journ. Amer, Med. A s80 . Chicago, October 15th, 1903

Griffths: Journ. Path. and Bacteriol., Edinburgh and London, 1901,

vii. 449 .

Hebb : Westminster Hosp. Rep., 1895, ix, 316.

Hewlett, A. W. : .Journ. Exper. Med., New York, 10)-1901, v, 319.

Keith, R. D. : Trans. Path Soc., London, 1905, lvi, 365.

Mlein : Lancet, 1899, 1i, 1297 .

Osler, W. : Principles and Practice of Medicine, 19c5, sixth edition, p. 340 .

Robson, A. W. Mayo : Med.-Chir. Trans., London, 1896, lxxix, 159

Rolleston and Trevor : Journ. Path. and Bacteriol., Kdinburgh and

Speese : Univ. Penn. Med. Bull., 1\&07, xix, 200.

\section{TWO CASES OF MULTIPLE INTESTINAL OBSTRUCTION.}

BY ROBERT RAMEEY, M.B., F.R.C.S.E.,

DISPENSARY SURGEON, GLASGOW ROYAL INFIRMARY.

IN the first of these cases the patient, a night watchman, aged 81 , stated that though for some years he had been subject to bronchitis in winter and for many years had a left inguinal hernia, he had been a very healthy man, the hernia giving no trouble. About $8 \mathrm{p} . \mathrm{m}$. on the evening preceding his admission the patient, being then on duty was suddenly, and without apparent cause, seized with severe abdominal pain. He was taken home. Vomiting commenced shortly afterwards and continued, pain later on being felt in the hernia and over the abdomen.

State on Admission. - He was in fair condition ; pulse about 100, with occasional irregularities; temperature normal ; marked faecal romiting was present.' The abdomen was much' distended and tense ; the large left inguinal hernis present was firm, painful, irreducible, dull on percussion, and had no impulse on coughing.

Operation.-Under chloroform the hernia was cut down on and on opening the sac a large quantity of clear serous fluid escaped; there was a loop of bowel in the sac, slightly distended and red, but having no marked appearance of strangulation; the ring was wide and the bowel easily returned. As this did not seem to afford sufficient explanstion of such marked faecal vomiting, a median laparotomy was performed, distended small bowel presented, and this was being followed down, led to a loop of ileum fixed tight lois, on the crecum, evidently being of the nature of an internal hernia ; this loop was almost black in colour, but on reduction appeared viable, so the abdomen was closed and the patient put back to bed:

Second Operation.-Faecal vomiting continued all night, and, as the patient was rapidly sinking, the abdomen was again opened in the morning, eight hours having elapsed since the former operation. Another impacted and strangulated nternal hernia was discovered, this time up in the region the splenic flexure, where the bowel had got caught in peritoneal pocket; this bowel was also nearly black, but was treated by simply replacing it in the abdomen

Rrsult.-After this the vomiting ceased, and in six hours the bowels moved. The patient remained free from pain, his temperature kept from $98^{\circ}$ to $100^{\circ}$, his pulse improved, and the day following operation his bowels moved again. On the fourth day his cough became very troublesome, and a dull patch was detected in one lung. This increased, and he died on the eighth day aiter the last operation. The following notes were made at the autopsy:

The body is that of an emaciated old man, and the arteries show signs of senile degeneration; there is an operation wound over the left inguinal region, which is almost healed; there is also one over the middle line of the abdomen, below the umbilicus; this one, though quite aseptic, shows very tion; both lungs are in a bote of hypostat is in good condrsolidation being marked at both bases. There was nothing of note in the other organs.

The second patient, a hammer boy, aged 18, stated that he had always been healthy, but seven years ago had been run over by a van, and had his abdomen injured. After this he was in hospital for eight weeks, but eventually made a perfect recovery.

On July 17th, eight days before admission to the infirmary, he was away for a day's trip, and next morning felt sick and had some abdominal pain; it was thought to be due to what he had eaten the day before. In the evening severe vomiting commenced, and had continued till admission. For the last forty-eight hours it had been faecal in character. Two enemata were given on the 19th with fair result, but since then the bowels had never acted, nothing whatever had been retained, and abdominal pain was excessive.

State on Admission.-He was in a desperate condition; his pulse very weak and about 104 in rate; his temperatur $99^{\circ}$; very marked faecal vomiting was present ; the abdomen was not markedly distended and no local tumour could be felt.

Operation.-Under chloroform an incision was made in the midale line, somswhat distended small intestine presented, and on following this down it was found to go in at the foramen of Winslow; almost $3 \mathrm{ft}$. of bowel was palled out through this foramen; at one part there was a slight mark of constriction but there was nothing which seemed sufficient to account for the symptoms, so a further search was made and a long, inflamed appendix was discovered twisted firmly round a par of the small intestine and evidently completely blocking it. The adhesions were broken through and the appendix removed ; the small bowel thus freed was about 6 in. away from the ileo-caecal valve, and it was much congested.

Result.-He lived about six hours after the operation, and during that time his bowels moved slightly; however, there was no proper rally. At the autopsy the following was observed : There was no marked distension of bowel, no obstruction,
intense congestion of a part of the lower end of the jejunum, which had a haemorrhagic appearance in places, no peritonitis nor ulceration of bowel. In the appendix region there was also marked congestion involving the stump of appendix and caput and especially the lower end of the ileum; inside the bowel at this part there was congestion of the Peyer's patches, withont nlceration, also enlarged retroperito Peyer's patches, felt. The other organs showed no marked pathological lesion.

Rrmarks. - In both these cases there seems no doubt that the vomiting and peristalsis induced by the primary obstruction were the causes which induced the secondary herniae. This possibility should be remembered, for in any violent vomiting we have a predisposing cause for an obstruction. If, therefore, we find what appears to be an insufficient obstruction, or in cases where an operation has not seemingly relieved the obstruction, the possibility of a second one must be borne in mind. As these secondary obstructions may not be very tight, and may resolve themselves with the general relaxation at death, it is possible that they account for some of the cases of so-called paralysis of the bowel where no peritonitis or obstruction is found after death.

My thanks are due to Dr. Adams for permission to treat these cases in his ward and also to publish the results.

\section{TWO NEW GENERA OF NEMATODES OCCASIONALLY PARASITIC IN MAN.}

By ROBERT T. LE[PER, M.B., F.Z.S., HEIMINTHOLOGIST TO THE LONDON SCHOOL OF TROPICAL MEDICINE.

THE helminthic affections of man are in not a few instances cases of accidental or occasional parasitism, the normal host being one of the domesticated lower animals more or less closely associated with him. Thus, Fasciola hepatica, Dicrocoelium lanceatum and Opisthorchis felineus among the Trematoda, Eustrongylus gigas, Ascaris mystax, and strongylus longe-vaginatus among Nematodes, and the 
Cestode larva Echinococcus, are known to produce in man all the pathological effects their presence incites in their proper hosts. Probably, also, as to some extent adventitious, we may likewise regard Paragonimus westermanii, Schistosomum japonicum, and Trichinella spiralis.

It is obvious, then, that in order to understand the nature and the relationships of the human parasites we must acquire intimate knowledge of the structure and life-histories of those of the lower animals. This is aptly illustrated by a comparative study of the Ascaris mystax, a parasite that has been reported but seldom in man, and that infests our domestic cats and dogs, and, according to the literature, most of the carnivora.

It is somewhat surprising, in view of the number and intimacy of pet cats and dogs in the home, that there are only nine records of the occurrence of cases of human infection: two in Ireland, England, and Germany; and one in Denmark, Hungary, and North America. This is possibly more on account of the parasite having been mistaken for an immature Ascaris lumbricoides than of its great rarity.

The most outstanding fexture by which an Ascaris mystax can be easily distinguished with the unaided eye is the spatulate shape of the head produced by two lateral membranous expansions of the cuticle, and it is because of these that the parasite has been designated the "winged" ascaris. The value of these structures as indicative of specific differences between the "winged" ascarids of various hosts has been much discussed and differed upon for the last hundred years. In his monograph of the genus Ascaris, published in 1896, Stossich included in his list of the synonyms of this parasite no less than fifteen other specific names ; some of these date from the period when it was considered that a different host was a sufficient guarantee for the specificity of the parasite, but many were based upon the shape of the alae. It was upon this character mainly that that profound observer, Rudolphi, who has been-aptly named the Linnaeus of Helminthology, based the differentiation of the species leptoptera (from the lion), marginata (from the dog), mystax (from the cat) and triquetra (from the fox), in his "Capite Alato" subsection of the genus Ascaris.

When Bellingham first found the Ascaris mystax in man he described it as a new species under the name Ascaris alata, because of differences he noted in the outline of the alae as compared with those of the "winged" ascaris of the cat. Cobbold, however, from an examination of similar worms from another case, concluded that the differences were merely variations occurring in individuals of the same species. This opinion became very generally accepted, and its application has gradually been extended until at the present time the winged ascaris of the $\operatorname{dog}(A$. marginata, Rudolphi), of the cat (A. mystax), and of the fox (A. triquetra) are all regarded as belonging to the same species, Ascaris mystax, or, as the nomenclaturists have it, Ascaris canis. This is the view adopted, as far as I can gather from their recent writings, by Blanchard, Railliet, Neumann, Braun, and Stiles.

Through the courtesy of the authorities of the Egyptian Government School of Medicine I had the privilege of working for several months of last year under Professor Looss in his laboratory at Cairo, and whilst so engaged came across, in a quantity of Ascaris lumbricoides sent from the post-mortem room of the Kasr-Ainy Hospital, four smaller forms differing from young lumbricoides in their peculiar firmness and resilience, and, on closer examination, in the spatulate outline of the anterior end of the body, and I concluded, for the nonce, that this was another case of Ascaris mystax in man. But on more carefully examining the anterior end of one of the specimens under a higher power of the microscope I was struck by the fact that the alae appeared rather linear, and did not bulge posteriorly in the manner of the typical Ascaris mystax of the cat. On the other hand, they were apparently identical with other specimens of ascaris that had been obtained some time previously from a dog. From a comparison of a large number of examples from the cat and from the dog, I became convinced that these differences in outline were not merely individual variations, but distinctive of two separate species.

With specimens cleared by the method elaborated by Dr. Looss I was able to determine the existence of other and hitherto unnoticed differences in external and internal structure correlated with those exhibited by the alae of the two forms. Indeed, it became apparent that they could scarcely be included in the same natural genus, for several of the dividing characters were those of generic import.

This inference was fully borne out by an examination of samples of so-called Ascaris mystax from other carni vores. It was easy: to range these into two groups, namely, those showing essentially the same internal anatomy as the true Ascaris mystax - that is, of the catand those agreeing similarly with the Ascaris mystax vel marginata of the dog. When such an arrangement had been made it was still a matter of liftle difficulty to distinguish the various species from one another, by other structurally less important characters, these being in fact those relied on more than a hundred years ago by Rudolphi, and, in addition, the contours of the lip structures and the oesophagus. We have, then, in the winged ascarides not merely two or more varieties of one species, but, to my thinking, several species belonging to two distinct genera, both of which are characterized by the presence of lateral expansions of the cuticle at the anterior end of the body. For these genera I propose the following names :

Belascaris, n.g. 1907, having as type Ascaris mystax (Zeder), and showing in all the species of the genus the following characters, collectively and individually : Anterior end of the body in preserved specimens bent ventrally. Outicle coarsely striated. Oesophages with distinct bulbous portion coarsely striated. Oesophagus with distinct bulbous portion posteriorly containing nuclei of oesophageal glands. Tail of a closed fist with the forefinger semiextended. On the bulging portion immediately behind the anus is a pair of single papillae with sunken caps, and on the finger-like tail two further pairs ventrally and two laterally, the tips of which apparently, from preserved specimens, support a slight expansion of cuticle. The colls of the testis are situated in the anterior half of the body cavity, differing in the various species in the limit of their forward extension. There is a species in the limit of their forward extension. There is a remarkably long "vesicula seminalis" and short ejaculatory duct. In the female the genital opening is situated in the
anterior part of the body, and the eggs have a corrugated shell.

To this genus belong Ascaris mystax (Zeder), Ascaris triquetra (Rudolphi's type specimens), and also a large new species from the Egyptian fox. From the brief published may be ascribed to the genus, as may also Ascaris leptoptera (Rudolphi).

Toxascaris; n.g. 1907. Type Ascaris leonina (v. Linstow) has the following distinctive characters common to the varlous species : The anterior end of the body is, - in preserved specimens, bent dorsally. The cuticle is finely striated. The oesophagus is simple and opens directly into the intestine without any intervening bulbous portion. The palps of the lips are distinctly club-shaped terminally. In the male the tail tapers to an acicular tip without any ventral retrusion behind the anus. The post-anal papillae are arranged in two groups, a ventral set of paired papillae continuous in line with the preansl row on each side of the body, and a lateral set, arranged as it were one at each corner of a triangle on the outer aspect of the tail. In all there are six pairs of post-ansl papillae, three lateral and three ventral, and of the ventral the pair succeeding the anus is double. The coils of the testis lie in the anterior part of the posterior half of the body. The tubular seminal vesicle is long, though short relative to that in Belascaris. The ejaculatory duct remains short. The genital opening in the femsle is found at about the centre of the body and the eggs are oval and have a smooth capsule.

The genus thus defined comprises the species: Ascaris marginata (Rudolphi), Ascaris leonina (ve. Linstow), Ascaris tigridis (Gmelin), and a further species from the Sudan not yet published.

The definition and illustration of the various characters distinguishing the carnivore species of these genera from one another can be more appropriately dealt with in another place as being of purely zoological interest. The object of the present note is to record, apparently for the first time, the occurrence of the "dog" ascaris as a human parasite as well as the "cat" ascaris, and to show that a study of the minuter structure of the ascarids of carnivores reveals the fact not only that those of the cat and of the dog are undoubtedly apecifically distinct, but that they actually belong to different genera. It gives me, too, an earlier opportunity than the fuller publication of $\mathbf{m y}$ work there could possibly have afforded to acknowledge the very generous facilities put in my way by the director and the staff of the Government School of Medicine at Cairo, and to express my gratitude to Dr. Looss, the 
Professor of Helminthology, for the unselfish way in which he, at the expense of much time and patience, initiated me into those special methods of work and thought that in his hands have already so greatly enriched helminthological literature.

\section{THE X-RAY TREATMENT OF RINGWORM OF THE SCALP :}

\section{SINGULAR COINCIDENCE OF MEASLES WITH} THE DEFLUVIUM OF THE HAIR.

\author{
BY J. M. H. MACLEOD, M.D.,
}

ASBISTANT PHYGICIAN FOR DISEASES OF THE SKIN, CHARING CROSS HOSPITAL ; PHYSICIAN TO THE SKIN DEPARTMENT, VICTORIA HOSPITAL FOR CHILDREN.

THE $x$-ray treatment of ringworm of the scalp has now passed through the experimental stage, and become recog nized as the most rapidly effective mode of treating the disease, and if properly done by recent methods, it has been shown to be comparatively free from risks. The so. called single exposure method, thanks to the work of Sabouraud and others, has replaced the more ancertain method of repeated exposures and fractional dosage. So certain and well regulated has the dosage become, that the operator now expects the defluvium of the hair from the exposed area to take place on about the sixteenth day without any marked inflammatory disturbance, only occasionally a transient hyperaemia for a few days before the hairs fall out. Consequently, when any marked hyperaemia occurs, it is naturally a source of great anxiety, suggesting the possibility of an overdosage of the rays, or the previous employment of some irritant to the scalp such as tinctare of iodine. Recently I had the alarming experience of an erythema occurring on the exposed areas in the scalps of two boys just as the hair was falling out, which.was so marked as to cause considerable anxiety, but which turned out to be due to the singular coincidence of an eruption of measles with the defluvium of the hair. This unusual experience seems to be worthy of recording.

Towards the end of last October, two boys, aged respectively 9 and 4 years, suffering from small-spored ringworm of the scalp, were sent up to me from the country for $x$-rsy treatment. In both of them an eruption of measles appeared on the exposed areas of the scalp as the hair was falling out. The followpose are brief notes of the cases:

CASE I.-Aged 9 years. Suffering from tinea tonsurans due to Microsporon audouini. The pstches of ringworm were confined to the frontal and occiptal regions, and could be included in two exposures with a circular localizer of $7 \mathrm{~cm}$. diameter. The exposures were given on October 27 th. On November 14th the hair had began to fall out from the exposed areas and it was noted that the skin of both areas presented a vivid erythema. This erythema was not of the mild diffuse type usually associated with the falling out of the hair, but was mottled in character and consisted of irregularly-shaped red macules, or slightly raised lesions, somewhat deeper in tint in macules, or slightly raised lesions, somewhat deeper in tint in the centre and varying in size from a pin's head to about 4 in.
in diameter. The presence of the eruption was not associated in diameter. The presence of the eruption was not associated boy was out of sorts; he complained of headache and coryza, and had a temperature of $101^{\circ} \mathrm{F}$. He was sent to bed and next morning a typical measles rash had developed on the forehead, behind the ears, on the sides of the neck, and was rapidly spreading on to the chest and back. I saw the case again on November 28 th in consultation with Dr. Owen Lankester, ond found that the measles rash had disappeared and that the hyperaemia had gone from the exposed areas, which were quite hyperaemia had gone from the exposed areas, which were quite case was that the measles eruption was first noticed on the exposed areas where the hair was falling out, and was not present to any extent elsewhere on the scalp. The hair had begun to grow by the middle of January and he was allowed to return to school.

CASE II.-Boy, aged 4 years, younger brother of other case, suffering from extensive tines tonsurans due to Microsporon audouini. The ringworm was much more widely distributed than in the former case and it was necessary to give eight single exposures of areas $7 \mathrm{~cm}$ in diameter to include it all. one small patch of ringworm had to be excluded from the $x$-ray exposure, as it had been irritated by previous treatment. The exposures were given on October 25th, 31st, and November 1st. On November 14th the hair had begun to come out of the areas first exposed, and a mottled erythema associated with the same general symptoms as affected the elder brother had developed, but they were more severe in character. Next day the measles eruption had become generalizad over the sk n. On November 28 th the measles rash had disappeared, and the exposed areas were bald. The case was not quite so satisfactory as the previous one, as the unexposed patch had to be needled on several oceasions with croton oil, and also a few stumps which had been left between two contiguous
exposed areas. The hair had begun to grow by the middle of January.

These cases were of great interest; on account of the measles eruption appearing on the areas rendered temporarily bald by the $x$ rays. When the eruption was first seen in this situation, in spite of the catarrh and temperature associated with it, the possibility of its being measles did not occur to me, and some unusual form of $x$-ray dermatitis suggested itself. This anxiety regarding the cases was, however, dispelled next morning when the eruption had come out fully.

\section{A PLEA FOR THE USE OF TUBERCULIN WITHIN AND WITHOUT SANATORIUMS.}

BY W. CAMAC WILKINSON, M.D.LOND., F.R.C.P., LECTURER IN MEDICINE, UNIVERSITY OF SYDNEY; PHYSICIAN, ROYAL PRINCE ALFRED HOSPITAL.

INFECTIOUS diseases of specific origin are the result of an affinity existing between the specific cause or its product or both and the tissue elements of the man or animal The result of the disease depends on the action and reaction of these two essential factors. If the specific cause is very virulent or very abundant, it overpowers the vitality of the invaded tissues and destroys the organism. On the other hand, the resisting energy of the tissues may overpower the agents of disease and either destroy them or neutralize their dangerous products. Tubercle bacilli, the specific cause of all forms of tuberculosis, manifest a remarkable affinity for certain parts of the human body, notably the lungs, and the result of tuberculous disease of the lungs depends on the virulence and number of tubercle bacilli and the resisting energy of the invaded tissues.

In the treatment of such an infectious disease there are two rational methods-one directed against the specific cause and therefore called specific, the other aiming rather at strengthening the resisting energy of the invaded tissues. These two distinct methods of specific and general treatment should be combined if we wish to get the best results.

The spesific method of treating pulmonary tuberculosis consists essentially in the use of tuberculin in its various forms, which helps to destroy the bacillus and to neutralize its toxic effects. This method is in fact a process of active i mmunization entirely different to the antitoxic treatment 0 diphtheria, in which the antitoxin is supplied ready made. In principle there is no difference between the tuberculin treatment for the purpose of curing tuberculosis and the use of Haffkine's fluid or similar agents for the purpose of preventing for a short time such diseases as plagne, cholera or typhoid fever. If, then, the method is advocated in order to protect a healthy person against a disease, which in a mathematical sense he has a very small chance of contracting, it is not unreasonable to urge the use of the method if it offers even a small chance of cure to one who has already fallen a viction to the disease. Those who have used and advocated the use of specific prophylactic fluids containing germ products for the prevention of plague cannot with any show of consistency oppose the use of tuberculin, which is, after all, merely, a vegetable product of the living tubercle bacillus. Many are, in their ignorance, guilty of this strange inconsistency. On the other hand, I may disarm some opposition by saying at the outset that the extraneous use of tuberculin is not the one only indispensable means of curing tuberculosis, even in an anatomical sense We know of no disease in which death is inevitable. Always some individuals are ordained by Nature or strong enough to survive an attack of the most virulent disease Plague does not kill all its victims; nor yet tetanus or anthrax. This power to resist lies in the tissues. Let us go a little further. This power to resist depends upon the ability of the tissues to produce a sufficiency of antibodis 8 which either kill the specific agency or render their produc's harmless It is too often forgotten that the very and only cause of the production of these antibodies in the tissues is the specific cause of the disease. The disease works out. its own cure by means of its own cause. Not only the disease but even the mechanism of immunity 